\title{
Single- and multiple-dose pharmacokinetics of inhaled indacaterol in healthy Chinese volunteers
}

\author{
Ji Jiang $\cdot$ Lilly Li $\cdot$ Hequn Yin $\cdot$ Ralph Woessner • \\ Corinne Emotte $\cdot$ Ruobing $\mathrm{Li} \cdot$ Sanjeev Khindri $\cdot$ \\ Hu Pei
}

Received: 24 July 2013/Accepted: 26 March 2014/Published online: 6 April 2014

(c) The Author(s) 2014. This article is published with open access at Springerlink.com

\begin{abstract}
Indacaterol is an inhaled, ultra-long-acting $\beta_{2}$-agonist that provides 24 -h bronchodilation with oncedaily dosing in patients with chronic obstructive pulmonary disorder. This study evaluated the pharmacokinetics, safety, and tolerability of multiple daily inhaled doses of indacaterol 150 or $300 \mu \mathrm{g}$ once daily in healthy Chinese volunteers. This was a single-center, randomized, doubleblind, multiple-dose, parallel-group study, placebo-controlled trial including two doses of indacaterol: 150 and $300 \mu \mathrm{g}$. Serum indacaterol was quantified using high-performance liquid chromatography-mass spectrometry with a lower limit of quantification of $0.01 \mathrm{ng} / \mathrm{mL}$. The pharmacokinetic parameters were analyzed using non-compartmental analysis and included $C_{\max }, T_{\max }$, and $\mathrm{AUC}_{0-24 \mathrm{~h}}$ on Day 1 and $\mathrm{AUC}_{0-24 \mathrm{~h}, \mathrm{ss}}, C_{\mathrm{max}, \mathrm{ss}}, C_{\mathrm{min}, \mathrm{ss}}, C_{\mathrm{av}, \mathrm{ss}}, T_{\mathrm{max}, \mathrm{ss}}, T_{1 / 2}$, $T_{1 / 2 \text {,acc }}, \mathrm{CL} / \mathrm{F}, V_{\mathrm{z}} / F$, and $R_{\text {acc }}$ on Day 14 (after repeated once-daily doses). Safety analyses were recorded using physical examination, biochemical tests, and ECG. Indacaterol steady state was achieved after 12-14 days of
\end{abstract}

J. Jiang $\cdot$ H. Pei $(\bowtie)$

Phase I Unit, Clinical Pharmacology Research Centre,

Peking Union Medical College Hospital, Beijing, China

e-mail: hupei@pumch.cn

L. Li · R. Li

Novartis Institutes for Biomedical Research, Shanghai, China

H. Yin

Novartis Pharmaceuticals Corporation, East Hanover, NJ, USA

R. Woessner - C. Emotte

Novartis Institutes of Biomedical Research, Basel, Switzerland

S. Khindri

Novartis Horsham Research Centre, Horsham, UK daily dosing. The mean effective half-life of indacaterol (based on drug accumulation at steady state) was 33.9 and $35.8 \mathrm{~h}$ for 150 and $300 \mu \mathrm{g}$, respectively. Systemic exposure to indacaterol increased 1.27 and 1.34-fold between the 150- and 300- $\mu \mathrm{g}$ doses on Day 1 (first dose) and Day 14 (repeated dose), respectively. Indacaterol 150 and $300 \mu \mathrm{g}$ were safe and well tolerated in these volunteers. The pharmacokinetics of multiple inhaled doses of indacaterol 150 and $300 \mu \mathrm{g}$ (for 14 days) were consistent with moderate systemic accumulation at steady state after repeated once-daily inhalation in healthy Chinese volunteers.

Keywords Indacaterol - Pharmacokinetics - Chinese population $\cdot$ Healthy volunteers

\section{Introduction}

Chronic obstructive pulmonary disease (COPD) is currently the fourth leading cause of death in the world and is estimated to rank fifth by 2020 in burden of disease worldwide (GOLD 2013). It is also an increasing public health concern in China (Fang et al. 2011). In a nationwide cross-sectional survey, the prevalence of COPD in China was found to be $8.2 \%$ in people aged 40 years or older (Zhong et al. 2007).

Inhaled bronchodilators are central to the treatment of stable COPD (GOLD 2013). Short-acting bronchodilators, such as salbutamol (a $\beta_{2}$-adrenoceptor agonist) and ipratropium (an anticholinergic), are recommended for use, as needed, by patients with mild COPD. Regular use of longacting bronchodilators is recommended for moderate and more severe COPD. These include the long-acting $\beta_{2}$-adrenoceptor agonists (LABAs) salmeterol and formoterol, which require twice-daily administration, and the 
muscarinic antagonist tiotropium, which is taken once daily (Fang et al. 2011).

Indacaterol maleate is a novel, inhaled ultra-LABA that provides 24-h bronchodilation with a fast onset of action from the first dose and once-daily dosing in patients with COPD (Cazzola et al. 2005; Kinoshita et al. 2012; Dahl et al. 2010; Kornmann et al. 2011). Once-daily treatment with indacaterol provided a significantly greater bronchodilator effect than currently marketed LABAs such as formoterol (Foradil ${ }^{\circledR}$ ) and salmeterol (Serevent ${ }^{\circledR}$ ) and was at least as effective in improving symptoms and health status (Dahl et al. 2010; Kornmann et al. 2011). Indacaterol is formulated as inhalation powder hard capsules for pulmonary administration and delivered using a single-dose dry-powder inhaler (SDDPI), the Breezhaler ${ }^{\circledR}$ (EU), Neohaler ${ }^{\circledR}$ (US) (Onbrez ${ }^{\circledR}$ and Arcapta $^{\circledR}$, respectively). This device has a low air-flow resistance to ensure that patients with severe lung conditions are able to use the device effectively (Pavkov et al. 2010; Feldman et al. 2010). Breezhaler $^{\circledR}$ has been shown to deliver a consistent dose irrespective of disease severity and age, with no reported device failures in clinical trials (Feldman et al. 2010).

Indacaterol has been approved for use in the maintenance treatment of patients with COPD at doses ranging from 75 to $300 \mu \mathrm{g}$ once daily in 85 countries worldwide, including China, Japan, the United States of America, and the European Union. The pharmacokinetics of indacaterol have been comprehensively characterized in Caucasian and Japanese patients with COPD and healthy volunteers (Hosoe et al. 2011; EU SMPC).

This is the first study that has been designed to determine the pharmacokinetics, safety, and tolerability of multiple daily inhaled doses of indacaterol in healthy Chinese volunteers.

The primary objective of the present study was to characterize the serum pharmacokinetics (PK) of indacaterol in healthy Chinese volunteers following single and repeated once daily inhaled administration of indacaterol 150 and $300 \mu \mathrm{g}$ delivered via an SDDPI. Further objectives of the study included safety, tolerability and efficacy assessments.

\section{Methods}

\subsection{Study design}

This was a single center, randomized, double-blind, multiple-dose, parallel group study, using a placebo control and two doses of indacaterol 150 and $300 \mu \mathrm{g}$. The study protocol and all amendments of the study were reviewed and approved by the Independent Ethics Committee of Peking Union Medical College Hospital, Beijing, China.
The study was conducted according to the ethical principles of the Declaration of Helsinki. Written and signed informed consent was obtained from each subject before any study-specific screening procedures were performed.

\subsection{Study population and randomization}

Healthy male and female Chinese subjects aged between 18 and 45 years (incl.) and weighing at least $50 \mathrm{~kg}$ with a body mass index within the range of $18-27 \mathrm{~kg} / \mathrm{m}^{2}$ were included in the study. Subjects were defined as Chinese if they had both parents and grandparents of Chinese descent. Exclusion criteria included any use of prescription drugs, herbal supplements within 4 weeks prior to initial dosing and/or over-the-counter medication or dietary supplements (including vitamins) within 2 weeks prior to initial dosing; pregnant or lactating women; and smokers who reported cigarette use of more than 10 cigarettes per day. The study randomized 32 subjects; 12 each into the two active treatment groups, indacaterol $150 \mu \mathrm{g}$ and indacaterol $300 \mu \mathrm{g}$, and eight to placebo for comparative safety assessment. The designated randomization ratio was chosen to maximize the number of subjects on each active dose within the recommended 8-12 subjects per treatment group requirement in China's State Food and Drug Administration (SFDA) guidelines (SFDA 2005).

A single inhaled dose of indacaterol (150 or $300 \mu \mathrm{g}$ ) or matching placebo was administered daily as single gelatinous capsules for 14 consecutive days in the morning, using the Breezhaler ${ }^{\circledR}$ device.

\subsection{Bioanalytics}

Pharmacokinetic venous blood samples were collected on Days 1 and 14, at pre-dose, and at 0.08, 0.25, 0.5, 1, 2, 4, 8, 12 , and $24 \mathrm{~h}$ post dose. Additional samples were collected at $36,48,120$, and $168 \mathrm{~h}$ post dose on Day 14. Trough pharmacokinetic blood samples were collected on Days 7, 10, and 12 before dosing. All blood samples were collected into silica-coated polypropylene collection tubes and left to clot at room temperature for $20 \mathrm{~min}$. The samples were then centrifuged at $2,500 \mathrm{~g}$ for $10 \mathrm{~min}$ to separate the serum. Serum samples were then stored at less than $-20{ }^{\circ} \mathrm{C}$ in polypropylene tubes until analyzed.

Indacaterol concentrations in serum were determined by high-performance liquid chromatography-mass spectrometry with lower limit of quantification (LLOQ) of $0.01 \mathrm{ng} /$ $\mathrm{mL}$ using $100 \mu \mathrm{L}$ of human serum.

\subsection{Pharmacokinetic analysis}

All subjects who provided at least one evaluable determination of $C_{\max }$ and/or $\mathrm{AUC}_{0-24 \mathrm{~h}}$ on Day 1 and/or Day 14 
along with actual dose and sampling time information were included in the pharmacokinetic data analysis.

The following pharmacokinetic parameters were determined for indacaterol: $C_{\max }$ (maximum serum drug concentration), $T_{\max }$ (time to reach $C_{\max }$ ), and $\mathrm{AUC}_{0-24 \mathrm{~h}}$ (area under the serum drug concentration-time curve from time 0 to $24 \mathrm{~h}$ post dose) on Day 1; $\mathrm{AUC}_{0-24 \mathrm{~h}, \mathrm{ss}}$ (the $\mathrm{AUC}$ during a dosing interval ( $\tau=24 \mathrm{~h}$ ) at steady-state), $C_{\max , s s}$ (maximum steady-state serum drug concentration), $C_{\text {min,ss }}$ (minimum steady-state serum drug concentration), $C_{\mathrm{av}, \mathrm{ss}}$ (average steady-state serum drug concentration), $T_{\max , s s}$ (time to reach $C_{\max }$ at steady state), $T_{1 / 2}$ (elimination halflife associated with the terminal slope of a semi logarithmic concentration time curve), $T_{1 / 2 \text {,acc }}$ (effective half-life determined according to Boxenbaum and Battle (1995), based on drug accumulation at steady state), $C_{\mathrm{L} / \mathrm{F}}$ (the total body clearance), $V_{\mathrm{Z} / \mathrm{F}}$ (the apparent volume of distribution), and $R_{\text {acc }}$ (accumulation ratio) after repeated once-daily doses on Day 14.

$C_{\max }, T_{\max }, \mathrm{AUC}_{0-24 \mathrm{~h}}$ were determined on Day 1 while on Day $14, \mathrm{AUC}_{0-24 \mathrm{~h}, \mathrm{ss}}, C_{\mathrm{max}, \mathrm{ss}}, C_{\mathrm{min}, \mathrm{ss}}, C_{\mathrm{av}, \mathrm{ss}}, T_{\max , \mathrm{ss}}, T_{1 / 2}$, $T_{1 / 2, \text { acc }}, C_{\mathrm{L} / \mathrm{F}}, V_{\mathrm{Z} / \mathrm{F}}, R_{\text {acc }}$ were measured.

All parameters except $R_{\text {acc }}$ and $T_{1 / 2 \text {,acc }}$ were calculated using WinNonlin Professional (Version 5.2, Pharsight Corp., Mountain View, California). $R_{\text {acc }}$ and $T_{1 / 2 \text {,acc }}$ were determined using SAS Professional, version 8.2. $R_{\text {acc }}$ was calculated using AUC values obtained from a dosing interval according to the following equation:

$\left(\mathrm{AUC}_{0-24 \mathrm{~h}}\right.$, Day 14)/( $\mathrm{AUC}_{0-24 \mathrm{~h}}$, Day 1)]

Effective half-life $\left(T_{1 / 2 \text {,acc }}\right)$ was determined based on drug accumulation at steady state and calculated according to the following equation (Boxenbaum and Battle 1995):

$T_{1 / 2, \mathrm{acc}}=\ln 2 \cdot \tau / \ln \left[R_{\mathrm{acc}} /\left(R_{\mathrm{acc}}-1\right)\right]$,

where $\tau$ is the dosing interval and $R_{\text {acc }}$ is the AUC accumulation ratio at steady state.

\subsection{Safety and tolerability analysis}

Safety and tolerability assessments included recording all adverse events (AEs) and serious AEs. Additional safety assessments included monitoring of vital signs, electrocardiogram (ECG) recordings, and study of blood chemistry, urinalysis, and hematology. AE data, laboratory data for hematology, blood biochemistry, urinalysis, ECG results, and measurements of vital signs were summarized descriptively by treatment group.

\subsection{Statistical analysis}

The dose-normalized geometric mean ratio (300:150) for all PK parameters was estimated by back transforming the values of the estimated mean difference and $90 \%$ confidence interval of the 300- and $150-\mu \mathrm{g}$ doses (that were calculated using analysis of variance). Change from baseline (0-h measurement on Day 1) in heart rate, QTcF, serum potassium, and blood glucose were compared between each dose of indacaterol and placebo at each postdose time point using an analysis of covariance model with baseline as covariate. Geometric mean concentrations at any given time point were only calculated if all individual concentrations were $\geq$ LLOQ. Summary statistics were provided for all safety and tolerability data.

\section{Results}

\subsection{Study population}

A total of 32 volunteers were enrolled into the study, with 27 males $(84.4 \%)$ and 5 females $(15.6 \%)$. The demographic characteristics of the patients are shown in Table 1 and were well balanced across dosing groups. All 32 subjects completed the study. There were no significant protocol deviations during the conduct of the study.

\subsection{Pharmacokinetic results}

Following the single or multiple dose inhaled administration of indacaterol 150 and $300 \mu \mathrm{g}$ for 14 days, indacaterol was absorbed rapidly following inhalation, with a median time to reach peak serum concentrations of 15 min postdose (Table 2). A summary of the mean pharmacokinetic parameters of indacaterol at each dose level and sampling day is given in Tables 2 and 3, respectively.

Arithmetic mean serum concentration time profiles of indacaterol for each dose level (i.e. 150 and $300 \mu \mathrm{g}$ ) and sampling day (first dose, Day 1 and repeated dose, Day 14) are shown in Figs. 1 and 2.

For Day 14, the geometric mean [\% coefficient of variation (CV)] of $C_{\max , s s}$ was 0.28 (44.6) $\mathrm{ng} / \mathrm{mL}$ for the $150-\mu \mathrm{g}$ dose and $0.68(23.8) \mathrm{ng} / \mathrm{mL}$ for the $300-\mu \mathrm{g}$ dose (Table 4). The corresponding values for $\mathrm{AUC}_{0-24 \mathrm{~h}, \mathrm{ss}}$ were 2.36 (38.7) $\mathrm{h} \mathrm{ng} / \mathrm{mL}$ and 6.33 (25.4) $\mathrm{h} \mathrm{ng/mL,} \mathrm{respectively}$ (Table 4). The mean $\mathrm{AUC}_{0-24 \mathrm{~h}}$ accumulation ratio (Day 14-Day 1) was calculated as 2.6 and 2.7 for the 150- and $300-\mu \mathrm{g}$ doses, respectively (Table 3 ).

The trough concentrations increased up to Day 12 with the mean (SD) trough values ranging from $0.0574 \mathrm{ng} / \mathrm{mL}$ (19.6) on Day 7 to $0.0686 \mathrm{ng} / \mathrm{mL}$ (23.8) on Day 12 at $150 \mu \mathrm{g}$, and from $0.164 \mathrm{ng} / \mathrm{mL}$ (44.4) on Day 7 to $0.179 \mathrm{ng} / \mathrm{mL}(51.7)$ on Day 12 at $300 \mu \mathrm{g}$. However, there was little change between Days 12 and 14, indicating that the steady state was achieved after 12-14 days of daily dosing (Fig. 3). The systemic exposure to indacaterol 
Table 1 Summary of patient demographics by treatment group

\begin{tabular}{lllll}
\hline & Indacaterol $150 \mu \mathrm{g}(n=12)$ & Indacaterol $300 \mu \mathrm{g}(n=12)$ & Placebo $(n=8)$ & Total $(n=32)$ \\
\hline Age, years & $28.3(4.79)$ & $24.8(4.09)$ & $26.4(6.48)$ & $26.5(5.09)$ \\
Male/female $(\%)$ & $83.3 / 16.7$ & $83.3 / 16.7$ & $87.5 / 12.5$ & $84.4 / 15.6$ \\
Ethnicity (Chinese) $(\%)$ & 100 & 100 & 100 & 100 \\
Weight $(\mathrm{kg})$ & $65.5(7.79)$ & $61.8(8.19)$ & $63.0(8.69)$ & $63.5(8.06)$ \\
Height $(\mathrm{cm})$ & $168.0(7.53)$ & $169.0(6.30)$ & $166.0(5.60)$ & $168.0(6.51)$ \\
BMI $\left(\mathrm{kg} / \mathrm{m}^{2)}\right.$ & $23.3(1.85)$ & $21.6(2.42)$ & $22.8(2.70)$ & $22.5(2.34)$ \\
\hline
\end{tabular}

Data are mean (SD), except male/female and ethnicity which are $\%$

$B M I$ body mass index, $S D$ standard deviation

Table 2 Pharmacokinetic parameters of indacaterol following a single dose of inhaled administration of indacaterol 150 and $300 \mu \mathrm{g}$ on Day 1 in healthy Chinese subjects

\begin{tabular}{lll}
\hline & \multicolumn{1}{l}{ Indacaterol } \\
\cline { 2 - 3 } Pharmacokinetic variable & $150 \mu \mathrm{g}(n=12)$ & $300 \mu \mathrm{g}(n=12)$ \\
\hline$C_{\max }(\mathrm{ng} / \mathrm{mL})$ & $0.206(0.0568)$ & $0.518(0.0780)$ \\
$T_{\max }(\mathrm{h})$ & $0.25(0.25-1.00)$ & $0.25(0.25-0.25)$ \\
AUC $_{0-24 \mathrm{~h}}(\mathrm{~h} \mathrm{ng} / \mathrm{mL})$ & $0.974(0.252)$ & $2.43(0.408)$ \\
\hline
\end{tabular}

Data are expressed as mean (SD), except for $T_{\max }$ which are expressed as median (min-max)

$A U C_{0-24 h, s s}$ area under curve during a dosing interval $(\tau=24 \mathrm{~h})$ at steady-state, $C_{\max }$ maximum serum drug concentration, $T_{\max }$ time to reach $C_{\max }$

Table 3 Pharmacokinetic parameters of indacaterol following multiple doses of inhaled administration of indacaterol 150 and $300 \mu \mathrm{g}$ for 14 days in healthy Chinese subjects

\begin{tabular}{lll}
\hline Pharmacokinetic variable & Indacaterol \\
\cline { 2 - 3 } & $150 \mu \mathrm{g}(n=12)$ & $300 \mu \mathrm{g}(n=12)$ \\
\hline$C_{\mathrm{max}, \mathrm{ss}}(\mathrm{ng} / \mathrm{mL})$ & $0.299(0.116)$ & $0.697(0.168)$ \\
$C_{\mathrm{min}, \mathrm{ss}}(\mathrm{ng} / \mathrm{mL})$ & $0.0645(0.0311)$ & $0.182(0.0503)$ \\
$C_{\mathrm{av}, \mathrm{ss}}(\mathrm{ng} / \mathrm{mL})$ & $0.105(0.0381)$ & $0.272(0.0685)$ \\
$T_{\max , \mathrm{ss}}(\mathrm{h})$ & $0.25(0.25-0.50)$ & $0.25(0.25-0.50)$ \\
$\mathrm{AUC}_{0-24 \mathrm{~h}, \mathrm{ss}}(\mathrm{h} \mathrm{ng} / \mathrm{mL})$ & $2.51(0.914)$ & $6.52(1.64)$ \\
$R_{\mathrm{acc}}$ & $2.59(0.636)$ & $2.69(0.534)$ \\
$T_{1 / 2 \mathrm{acc}}(\mathrm{h})$ & $33.9(11.0)$ & $35.8(9.06)$ \\
$C_{\mathrm{L} / \mathrm{F}}(\mathrm{L} / \mathrm{h})$ & $67.9(25.6)$ & $48.7(12.0)$ \\
$V_{\mathrm{z} / \mathrm{F}}(\mathrm{L})$ & $11050(3506)$ & $8153(3023)$ \\
$T_{1 / 2}(\mathrm{~h})$ & $116(19.3)$ & $118(38.9)$ \\
\hline
\end{tabular}

Data are mean (SD) except for $T_{\max }$ which are median (min-max)

$A U C_{0-24 h, s s}$ area under curve during a dosing interval $(\tau=24 \mathrm{~h})$ at steady-state, $C_{\max , \text { ss }}$ maximum steady-state serum drug concentration, $C_{\text {min,ss }}$ minimum steady-state serum drug concentration, $C_{a v, s s}$ average steady-state serum drug concentration, $T_{\max , s s}$ time to reach $\mathrm{C}_{\max }$ at steady state, $T_{1 / 2}$ elimination half-life, $T_{1 / 2, a c c}$ effective half-life based on drug accumulation at steady state, $C_{L / F}$, the total body clearance, $V_{Z / F}$ the apparent volume of distribution, $R_{a c c}$ accumulation ratio

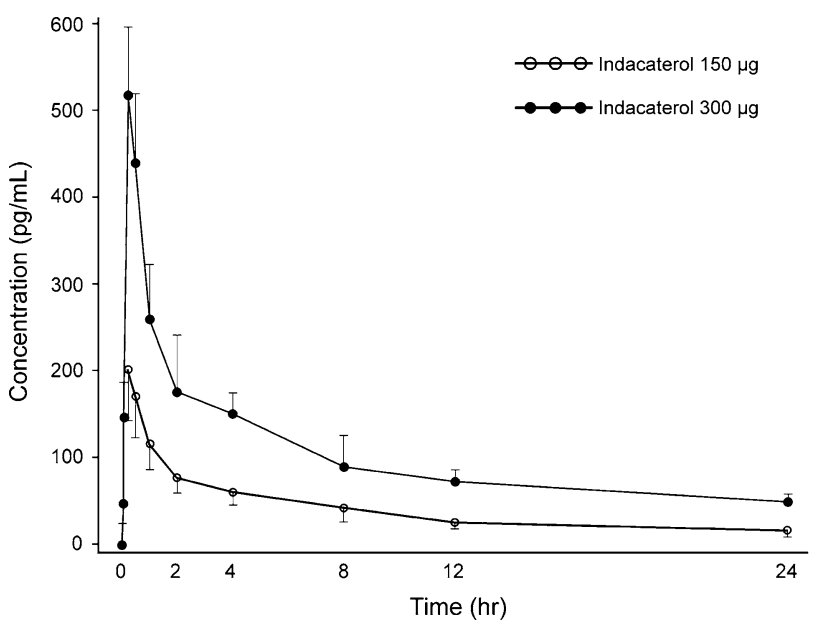

Fig. 1 Arithmetic mean (SD) serum concentration-time profile following single dose inhaled administration of indacaterol 150 and $300 \mu \mathrm{g}$ on Day 1 in healthy Chinese subjects

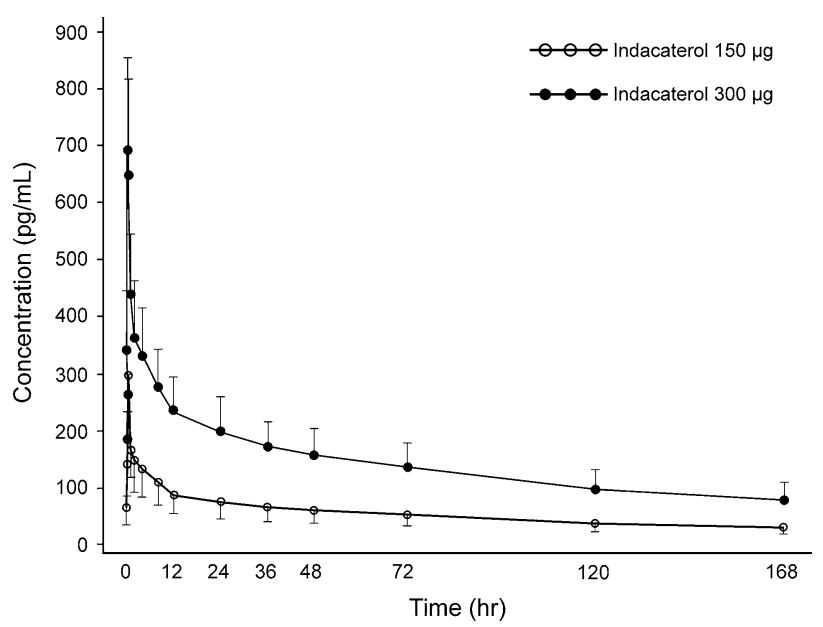

Fig. 2 Arithmetic mean (SD) serum concentration-time profile following multiple doses inhaled administration of indacaterol 150 and $300 \mu \mathrm{g}$ for 14 days in healthy Chinese subjects

increased between 1.27- and 1.34-fold for the 150-and $300-\mu \mathrm{g}$ doses (Table 4).

Based on the observed indacaterol AUC accumulation ratio for each subject, the effective half-life $\left(T_{1 / 2, \text { acc }}\right)$ of 
Table 4 Summary statistics for dose-proportionality evaluation of indacaterol 150 and $300 \mu \mathrm{g}$ for Days 1 and 14

\begin{tabular}{|c|c|c|c|c|c|c|c|}
\hline \multirow[t]{2}{*}{ Day } & \multirow[t]{2}{*}{ Pharmacokinetic variable } & \multirow[t]{2}{*}{ Unit } & \multicolumn{2}{|c|}{ Geometric mean (\%CV) } & \multicolumn{3}{|c|}{ Ratio of dose normalized geometric means $(300 \mu \mathrm{g}: 150 \mu \mathrm{g})$} \\
\hline & & & $150 \mu \mathrm{g}$ & $300 \mu \mathrm{g}$ & Estimate & Lower $90 \% \mathrm{CL}$ & Upper $90 \% \mathrm{CL}$ \\
\hline \multirow[t]{2}{*}{1} & $\mathrm{AUC}_{0-24 \mathrm{~h}}$ & $\mathrm{~h} \mathrm{ng} / \mathrm{mL}$ & $0.94(28.0)$ & $2.39(17.2)$ & 1.27 & 1.08 & 1.49 \\
\hline & $C_{\max }$ & $\mathrm{ng} / \mathrm{mL}$ & $0.20(28.8)$ & $0.51(15.8)$ & 1.29 & 1.10 & 1.51 \\
\hline \multirow[t]{2}{*}{14} & $\mathrm{AUC}_{0-24 \mathrm{~h}, \mathrm{ss}}$ & $\mathrm{h} \mathrm{ng} / \mathrm{mL}$ & $2.36(38.7)$ & $6.33(25.4)$ & 1.34 & 1.07 & 1.68 \\
\hline & $C_{\max , \mathrm{ss}}$ & $\mathrm{ng} / \mathrm{mL}$ & $0.28(44.6)$ & 0.68 & 1.23 & 0.96 & 1.56 \\
\hline
\end{tabular}

$A U C_{0-24 h}$ area under curve during a dosing interval $(\tau=24 \mathrm{~h})$ at steady-state, $C_{\max }$ maximum steady-state serum drug concentration, $s s$ steady state

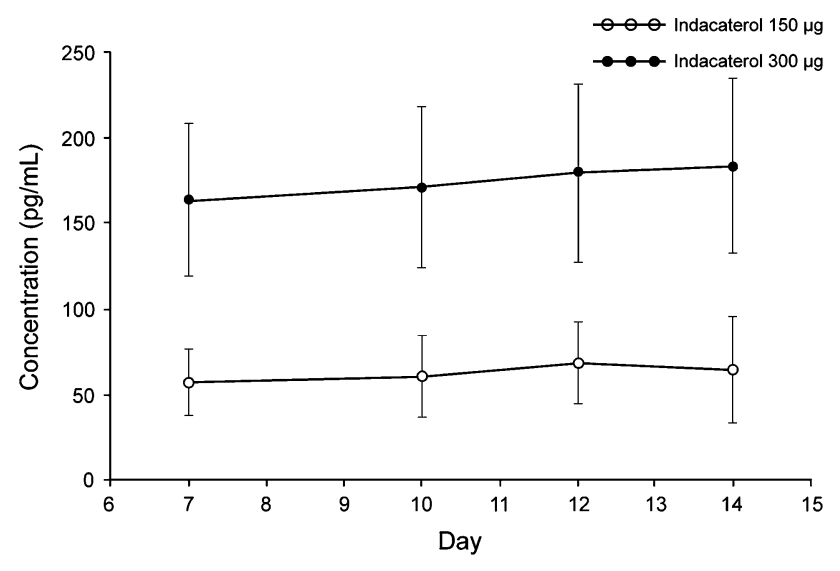

Fig. 3 Arithmetic mean (SD) serum trough concentrations after multiple doses inhaled administration of indacaterol 150 and $300 \mu \mathrm{g}$ in healthy Chinese subjects

indacaterol was determined for the 150- and 300- $\mu \mathrm{g}$ doses. The mean (SD) of $T_{1 / 2 \text {,acc }}$ was 33.9 (11.0) and 35.8 (9.06) hours, respectively. After 14 days of once-daily dosing, the mean terminal elimination half-lives were 116 and $118 \mathrm{~h}$, respectively.

\subsection{Safety results}

There were no meaningful differences between screening, baseline, and end-of-study vital signs. Individual values were almost entirely within the ranges specified for inclusion in the study and there were no deviations that were of clinical significance.

The overall incidence of AEs by preferred term is presented in Table 4. Most AEs were transient and mild in severity. The most frequently reported AE was cough [56 (98.2 \%) subjects; $150 \mu \mathrm{g}(n=6), 300 \mu \mathrm{g}(n=8)$, placebo $(n=1)$ ]. This event was suspected to be dose related although it also occurred in one patient receiving placebo. One volunteer from the indacaterol $300 \mu \mathrm{g}$ treatment arm reported epistaxis as an AE. No deaths or serious adverse events were reported. There were no clinically meaningful differences in least squares (LS) mean serum potassium or serum glucose all post-dose time-points for all treatments compared to placebo on Days 1 and 14. There were dosedependent increases in heart rate and QTcF interval which were consistent with the known effects of Indacaterol and not considered to be clinically meaningful.

\section{Discussion}

While the pharmacokinetics of indacaterol have been previously extensively studied in Caucasian and Japanese patients (Hosoe et al. 2011; EU SMPC) and healthy volunteers (Khindri et al. 2011), this is the first study to evaluate the pharmacokinetics of indacaterol following administration of single and repeated once-daily doses of 150 and $300 \mu \mathrm{g}$ in healthy Chinese volunteers. Following single (Day 1) and repeated (Day 14) inhalation, indacaterol was rapidly absorbed into the systemic circulation with the median time to maximum serum concentrations $\left(T_{\max }\right)$ occurring $15 \mathrm{~min}$ post inhalation for both doses. The early serum concentration peak is likely to reflect absorption via the lung indicating that a significant portion of the orally inhaled drug is delivered to and systemically absorbed via the target organ for topical COPD therapy. The systemic exposure to indacaterol, as characterized by $\mathrm{AUC}_{0-24 \mathrm{~h}}$ and $C_{\max }$, increased in a doseproportional manner with moderate accumulation upon repeated once-daily dosing as shown by the estimated AUC accumulation ratios of 2.6 and 2.7 for the $150-$ and $300-\mu \mathrm{g}$ dose groups which was within the range seen for indacaterol in other studies (Hosoe et al. 2011).

The disposition kinetics of indacaterol is multiphasic as shown by the mean concentration-time profiles in Fig. 1 . Systemic concentrations decreased rapidly within the first 4-8 $\mathrm{h}$ after inhalation, and more slowly thereafter. The concept of an effective half-life ( $\left.T_{1 / 2, \text { acc }}\right)$ of drug accumulation as proposed by Boxenbaum and Battle (1995), was applied to the data. In principle the effective half-life reflects the actual observed drug accumulation, as opposed to one or more aspects of exponential drug disposition, and is calculated from the AUC accumulation ratio and the dosing interval. The mean (SD) $T_{1 / 2 \text {,acc }}$ values determined for the 150 - and $300-\mu \mathrm{g}$ doses on Day 14 were 33.9 (10.9) 
and 35.8 (9.1) hours, respectively. The mean (SD) terminal elimination half-life $\left(T_{1 / 2}\right)$ values were $116(19.3)$ and 118 (39.0) hours for 150 and $300 \mu \mathrm{g}$, respectively, on Day 14.

In this study, the indacaterol steady state was achieved between 12 and 14 days of daily dosing. Indacaterol was detectable in serum immediately after inhalation. The ratio (300-150 $\mu \mathrm{g})$ of the dose-normalized geometric means for $C_{\max }$ and $\mathrm{AUC}_{0-24 \mathrm{~h}}$ on Days 1 and 14 was above 1.0 and ranged from 1.23 to 1.34 , indicating that exposure to indacaterol increased more than twofold between the 150- and 300- $\mu \mathrm{g}$ doses. Given the fact that this study was not powered to assess dose proportionality, the observed small deviations from doseproportionality appeared not to be clinically meaningful.

The finding that systemic concentrations of indacaterol rapidly decline to very low levels may be advantageous for the drug's safety profile, since there is little risk of sustained high systemic concentrations and/or significant drug accumulation during chronic dosing. The dissociation between the short residence time in the systemic circulation and the long duration of action of indacaterol (Hosoe et al. 2011; Khindri et al. 2011; Moen 2010) might be related to the fact that local drug load in the lung is required for maintenance of bronchodilation effect in the lung whilst systemic drug concentrations have little or no relevant contribution to the bronchodilator effect.

Multiple, daily inhaled doses of indacaterol in healthy Chinese subjects were well tolerated and had an acceptable safety profile. There were no serious or unexpected AEs. Cough was the most commonly observed treatment-related adverse event, consistent with previous clinical studies (Kinoshita et al. 2012; Dahl et al. 2010; Kornmann et al. 2011) as well as observations in healthy subjects from other Asian ethnic populations (Khindri et al. 2011).

\section{Conclusions}

In conclusion, the once-daily dosing of inhaled indacaterol in healthy Chinese volunteers produced a consistent and predictable pharmacokinetic profile. Indacaterol was systemically available shortly after inhalation. Systemic exposure to indacaterol increased in a dose-proportional manner from 150 to $300 \mu \mathrm{g}$ doses, with moderate accumulation upon repeated once-daily dosing. Multiple inhaled doses of indacaterol 150 and $300 \mu \mathrm{g}$ (for 14 days) were also found to be safe and well tolerated in healthy Chinese volunteers.

Acknowledgments The authors thank the healthy volunteers who took part and the staff at the participating clinical centre. The authors acknowledge Kavya Thelakkat, professional medical writer (Novartis), for assistance in preparation of this manuscript.

Conflict of interests All authors have completed the Unified Competing Interest form at http://www.icmje.org/coi_disclosure.pdf (available on request from the corresponding author) and declare: JJ and HP have received grants from National Program on Key Research Project of New Drug Innovation (2008ZX09312-016). HY, RW, CE, RL and SK are employees of Novartis.

Open Access This article is distributed under the terms of the Creative Commons Attribution Noncommercial License which permits any noncommercial use, distribution, and reproduction in any medium, provided the original author(s) and the source are credited.

\section{References}

Boxenbaum H, Battle M (1995) Effective half-life in clinical pharmacology. J Clin Pharmacol 35:763-766

Cazzola M, Matera MG, Lotvall J (2005) Ultra long-acting beta 2-agonists in development for asthma and chronic obstructive pulmonary disease. Expert Opin Investig Drugs 14:775-783

Dahl R, Chung KF, Buhl R et al (2010) Efficacy of a new once-daily long-acting inhaled beta2-agonist indacaterol versus twice-daily formoterol in COPD. Thorax 65:473-479

EU SMPC 2 European Medicines Agency (EMA): Indacaterol $\left(\right.$ Onbrez $\left.^{\circledR}\right)$ full prescribing information (EU) (2010). Available at: http://www.ema.europa.eu/docs/en_GB/document_library/ EPAR_-_Summary_for_the_public/human/001114/WC500053733. pdf. Last accessed 13th December 2012

Fang X, Wang X, Bai C (2011) COPD in China: the burden and importance of proper management. Chest 139:920-929

Feldman G, Siler T, Prasad N et al (2010) Efficacy and safety of indacaterol 150 microg once-daily in COPD: a double-blind, randomised, 12-week study. BMC Pulm Med 10:11. doi:10. 1186/1471-2466-10-11.:11-10

GOLD (2013) Global Initiative for Chronic Obstructive Lung Disease (GOLD). Global strategy for the diagnosis, management, and prevention of chronic obstructive pulmonary disease. 2011 update. http://www.goldcopd.org/uploads/users/files/GOLD_ Report_2013_Feb19.pdf. Accessed on 22nd Mar 2013

Hosoe M, Woessner R, Matsushima S et al (2011) Efficacy, safety and pharmacokinetics of indacaterol in Caucasian and Japanese patients with chronic obstructive pulmonary disease: a comparison of data from two randomized, placebo-controlled studies. Clin Drug Investig 31:247-255

Khindri S, Sabo R, Harris S et al (2011) Cardiac safety of indacaterol in healthy subjects: a randomized, multidose, placebo- and positive-controlled, parallel-group thorough QT study. BMC Pulm Med 11:31. doi:10.1186/1471-2466-11-31.:31-11

Kinoshita M, Lee SH, Hang LW et al (2012) Efficacy and safety of indacaterol 150 and 300 microg in chronic obstructive pulmonary disease patients from six Asian areas including Japan: a 12-week, placebo-controlled study. Respirology 17:379-389

Kornmann O, Dahl R, Centanni S et al (2011) Once-daily indacaterol versus twice-daily salmeterol for COPD: a placebo-controlled comparison. Eur Respir J 37:273-279

Moen MD (2010) Indacaterol: in chronic obstructive pulmonary disease. Drugs 70:2269-2280

Pavkov R, Mueller S, Fiebich K et al (2010) Characteristics of a capsule based dry powder inhaler for the delivery of indacaterol. Curr Med Res Opin 26:2527-2533

SFDA (2005) State Food and Drug Administration, P.R.China, Guideline No. [H] GCL 1-2. Technical Guideline of Clinical Pharmacokinetics Research on Chemical Drug (in Chinese)

Zhong N, Wang C, Yao W et al (2007) Prevalence of chronic obstructive pulmonary disease in China: a large, populationbased survey. Am J Respir Crit Care Med 176:753-760 